\title{
Pulmonary actinomycosis - the great imitator
}

\author{
Anna Grzywa-Celińska', Justyna Emeryk-Maksymiuk², Katarzyna Szmygin-Milanowska', \\ Elżbieta Czekajska-Chehab ${ }^{3}$, Janusz Milanowski \\ ${ }^{1}$ Chair and Department of Pneumonology, Oncology and Allergology, Medical University of Lublin, Poland \\ ${ }^{2}$ Chair of Internal Medicine and Department of Internal Medicine in Nursing, Medical University of Lublin, Poland \\ 3 I Department of Medical Radiology, Medical University of Lublin, Poland
}

Grzywa-Celińska A, Emeryk-Maksymiuk J, Szmygin-Milanowska K, Czekajska-Chehab E, Milanowski J. Pulmonary actinomycosis - the great imitator. Ann Agric Environ Med. 2018; 25(2): 211-212. doi: 10.26444/aaem/75652

\section{Abstract}

Pulmonary localisation represents only $15 \%$ of all cases of actinomycosis. The clinical symptoms and radiological changes of this disease are non-specific and sometimes it can be misdiagnosed, usually as tuberculosis, lung cancer or lung abscess. In the reported case, what might look like the lung cancer, finally turned out to be actinomycosis. The interesting case is presented of lung actinomycosis in a 77-year-old farmer, admitted to the Department of Pneumonology, Oncology and Allegology in Lublin due to a massive haemoptysis. CT scan of the chest showed, apart from other changes, the spicular consolidation in the right lung which aroused oncology vigilance. The diagnostic path, which was a real medical challenge, led to the diagnosis of actinomycosis. The process of diagnosis and consequent treatment, which led to the complete regression of clinical and radiological changes, is presented.

\section{Key words}

actinomycosis, imitator, lung cancer

\section{INTRODUCTION}

A 77-year-old farmer, a current smoker, treated for chronic obstructive pulmonary disease, was admitted to the Department of Pneumonology, Oncology and Allegology in Lublin, due to massive haemoptysis of several days' duration. A chest X-ray showed an area of lung consolidation about $21 \mathrm{~mm}$ in size in the lower part of the right hilus. Computed tomography (CT) of the chest was carried out, which, apart from emphysema and fibrosis, revealed spicular consolidation at the base of segment 2 of the right lung ( $29 \mathrm{~mm}$ in diameter), and an area of parenchymal consolidation in segment 8 of the right lung (size $28 \times 51 \mathrm{~mm}$ ), which was not present in a previous CT performed six months earlier. Additionally, the parenchymal area $(41 \times 40 \mathrm{~mm}$ in diameter $)$ was described in

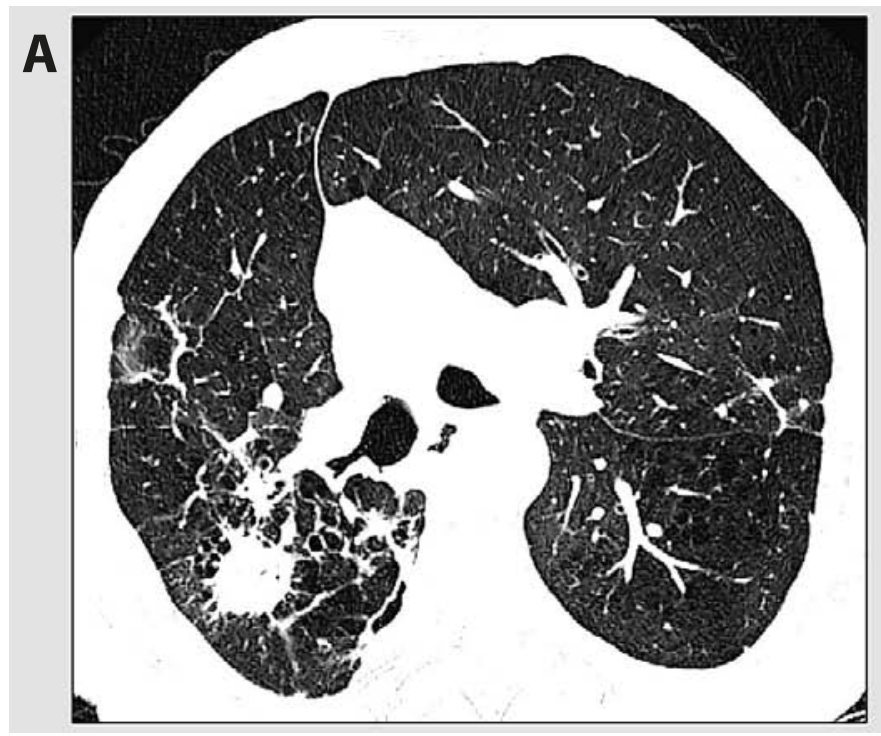

Address for correspondence: Anna Grzywa-Celińska, Chair and Department of Pneumonology, Oncology and Allergology, Medical University of Lublin, Poland E-mail: acelin@op.pl

Received: 24 February 2017; accepted: 8 May 2017; first published on June 2017 the left lower lobe with a centrally located cavity. There were a few enlarged lymph nodes in the mediastinum. Because of the clinical and radiological picture which aroused oncology vigilance, bronchoscopy was performed. The bronchoaspirate was taken for microbiological examination. A peribronchial lung biopsy was performed in segment 2 of the right lung. A pathology test showed no neoplastic tissue, but colonies of microorganisms morphologically corresponding to Actinomyces were found within the purulent masses. A culture on Schaedler agar was negative. Treatment with penicillin $\mathrm{G}$ was started with a dose of 18 million units/day for 3 weeks; next, it was continued with amoxicillin on an outpatient basis. During the initial intravenous antibiotic treatment the haemoptysis subsided and the well-being of the patient significantly improved.

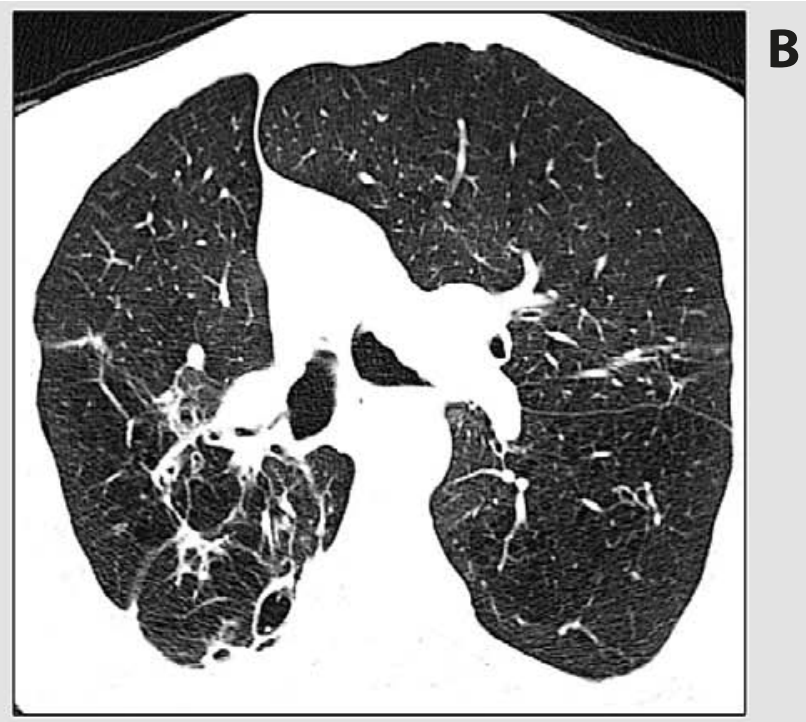

Figure 1.A. Chest CT imaging of lung actinomycosis before treatment Figure 1.B. Chest $\mathrm{CT}$ imaging of lung actinomycosis during treatment: significant regression of radiological changes 
After about 6 months of treatment, a CT showed a significant reduction in the spicular consolidation of segment 2 of the right lung (from $29 \mathrm{~mm}$ to $14 \mathrm{~mm}$ ), almost complete regression of the parenchymal densities in the left lower lobe $(41 \times 40 \mathrm{~m}$ to $20 \times 14 \mathrm{~mm})$, and total regression of the changes in segment 8 of the right lung (Fig $1 \mathrm{~A}, \mathrm{~B}$ ).

\section{DISCUSSION}

Actinomycosis of the lungs is a rare disease. After facialneck and ventro-pelvic variants, the pulmonary location is the third most frequent location of the infection with Actinomyces spp. [1] and represents approximately 15\% of all cases of actinomycosis $[2,3,4]$. Among others, the most common pathogen for humans is Actinomyces israelii [2]. Because these bacteria are saprophytes of the oral cavity, negligent hygiene may be the cause of the infection. Risk factors also include emphysema, chronic bronchitis, bronchiectasis, cigarette smoking, alcoholism, and disorders of carbohydrate metabolism $[1,3,5]$. The study patient had a poor oral hygiene as he was a smoker and did not avoid drinking alcohol.

The clinical symptoms and radiological changes of this disease are so non-specific that in some cases it can be a diagnostic riddle. The most common clinical manifestations, also observed in the presented patient, include: cough, coughing up phlegm, haemoptysis, chest pain, fever and weight loss [4]. In the presence of the above symptoms, differential diagnosis usually takes into account more prevalent diseases, such as lung cancer, TBC or pneumonia.

A tumour with or without cavities, which may 'mimic' cancer, is a pathology frequently encountered in the radiographic lung picture in the early stages of the disease $[1,4,5]$.
It is worth noting that Gram staining and histo-pathological examination of specimens from the affected organs are more sensitive than culture, which in over $50 \%$ of cases do not give a reliable answer due to previous antibiotic therapy, which inhibits the growth of Actinomycetes by coexisting bacteria, or the fact that incubation time is too short. It should be borne in mind that Actinomycetes have slow growth, and just 10-day culture allows for the exclusion of the infection with this microorganism [1].

Once the disease is confirmed, beta-lactam antibiotic given for 6-12 months is the therapy of choice.

It is very plausible that there are patients who are repeatedly hospitalized with typical, though non-specific symptoms of actinomycosis. In such cases, an extension of incubation time on microbiological surfaces, or pathology tests of the collected material, would give a chance for faster diagnosis and effective treatment of this disease.

\section{REFERENCES}

1. Valour F, Senechal A, Dupieux C, Karsenty J, Lustig S, Breton P, et al. Actinomycosis: etiology, clinical features, diagnosis, treatment, and management. Infect Drug Resist. 2014; 5, 7: 183-97. https://doi. org/10.2147/idr.s39601

2. Kim SR, Jung LY, Oh IJ, Kim YC, Shin KC, Lee MK, et al. Pulmonary actinomycosis during the first decade of $21^{\text {st }}$ century: cases of 94 patients. BMC Infect Dis. 2013; 14, 13: 216. https://doi.org/10.1186/14712334-13-216

3. Farrokh D, Rezaitalab F, Bakhshoudeh B. Pulmonary Actinomycosis with Endobronchial Involvement: A case report and literature review. Tanaffos 2014; 13 (1): 52-56.

4. Katsenos S, Galinos I, Styliara P, Galanopoulou N, Psathakis K. Primary bronchoplumonary actinomycosis masquaerading as lung cancer: Apropos of two cases and literature review, Case reports and Infectious diseases. 2015: 609637. https://doi.org/10.1155/2015/609637

5. Kaszuba M, Tomaszewska R, Pityński K, Grzanka P, Bazan-Socha S, Musiał I. Promienica imitująca zaawansowaną chorobę nowotworową. Pol Arch Med Wewn. 2008; 118, 10: 581-584. 